\title{
New Methods in Automatic Extracting
}

\author{
H. P. EDMUNDSON \\ University of Maryland, ${ }^{*}$ College Park, Maryland
}

ABSTRACT, This paper describes new methods of automatically extracting documents for screening purposes, i.e. the computer selection of sentences having the greatest potential for conveying to the reader the substance of the document. While previous work has focused on one component of sentence significance, namely, the presence of high-frequency content words (key words), the methods described here also treat three additional components: pragmatic words (cue words); title and heading words; and structural indicators (sentence location).

The research has resulted in an operating system and a research methodology. The extraeting system is parameterized to control and vary the influence of the above four components. The research methodology includes procedures for the compilation of the required dictionaries, the setting of the control parameters, and the comparative evaluation of the automatic extracts with manually produced extracts. The results indicate that the three newly proposed components dominate the frequency component in the production of better extracts.

KEY WORDS ANO PHRAsES: automatic extracting, automatic abstracting, sentence selection, document screcning, sentence significance, relevance, content words, key words, pragmatic words, cue words, title words, sentence location, research methodology, parameterization, comparative evaluation

CR Categonies: $3.10,3.69,3.71,3.72,3.74$

\section{Introduction}

Historical BACKGRound. Shortly after research in automatic translation began, interest was aroused in the possibility of automatically abstracting documents. Emphasis was placed on the production of indicative abstracts (i.e. abstracts that allow a searcher to screen a body of literature to decide which documents deserve more detailed attention) rather than on the production of informative abstracts (i.e. abstracts that can serve as substitutes for the document).

Also, it was hypothesized that an extract of a document (i.e. a selection of "significant" sentences of a document) can serve as an abstract. This hypothesis concerning the substitutability of extracts for abstracts has been discussed in $[1,2$, and 4]. All automatic abstracting methods to date have only extracted documents, i.e. the computer has selected sentences of the document and listed them in text order. Although it has been recognized for some time that this kind of automatic abstract might better be called an "automatic extract," "abstract" is often used as the generic term.

The original method of Luhn assigned weights to each sentence of the documen $t$

* Computer Science Center. The work reported here was initially conducted at ThompsonRamo-Wooldridge, Inc. (now Bunker-Ramo Corporation) with the support of the Rome Aix Development Center, Research and Technology Division, Air Force Systems Command, and was later continued at System Development Corporation under their Independent Researchi Program. 
according to statistical criteria, in fact, a simple function of the number of high frequency words occurring in the sentence. Common words such as "the," "and," "at," and "are" were disregarded because of their very high frequency alone, and the remaining words were assigned frequency weights that provided sentence weights for measuring sentence significance. The extracts produced by this strictly statistical method were of sufficient quality to encourage further research [3, 6]. However, a purely statistical method of producing extracts was suspected of being inadequate, and hence other methods were sought [7].

Summary of Present Study. The objective of this study was twofold: first, an extracting system to produce indicative extracts, and second, a research methodology to handle new text and new extracting critcria efficiently. The purpose of the present paper is to make the results of this study more readily available.

The research methodology comprised a study of the abstracting behavior of humans, a general formulation of the abstracting problem and its relation to the problem of evaluation, a mathematical and logical study of the problem of assigning numerical weights to sentences, and a set of extracting experiments employing cyclic improvement.

The extracting system developed uses four basic methods to produce automatic extracts of technical documents approximately 4000 words in length with the IBM 7090-7094 (and has been reprogrammed for the UNIVAC 1103A and CDC 1604). The automatic extracts are believed to be of sufficiently high quality to be used in the screening of large collections of documents. The system has been parameterized to permit modification of both prestored and generated word lists, to readjust weights assigned to text characteristics, to permit selection from 15 combinations of the four basic methods of extracting, and to alter the length of an automatic extract.

Three different evaluation schemes were applied to the resulting automatic extracts. Comparison of the automatic extracts and corresponding "target" extracts of 40 documents, which had not been used in the developmental research, showed that a mean of 44 percent of the sentences were coselected. Also, the mean similarity rating, in terms of a subjective evaluation of content by information type, was 66 percent. These are to be compared with a mean of 25 percent coselected sentences and a mean of 34 percent similarity rating between target $\mathrm{cx}$ tracts and random extracts, respectively. Statistical comparison of the automatic and the corresponding target extracts for the documents used in the developmental phase showed a mean of 57 percent coselected sentences with a standard deviation of 15 percent. A sentence-by-sentence analysis of the corresponding automatic and target extracts of 20 of these documents resulted in a judgment that 84 percent of the computer-selected sentences could be classified as extract-worthy; i.e. they would be worthy of selection in an extract of unrestricted length.

The following sections of this paper treat the research methodology used in the study, the extracting system, and the outlook for further research.

\section{Research Methodology}

Research Steps. The work reported here relies on the detection and use of sentence "significance." Within sentences selected by humans in forming an extract, 


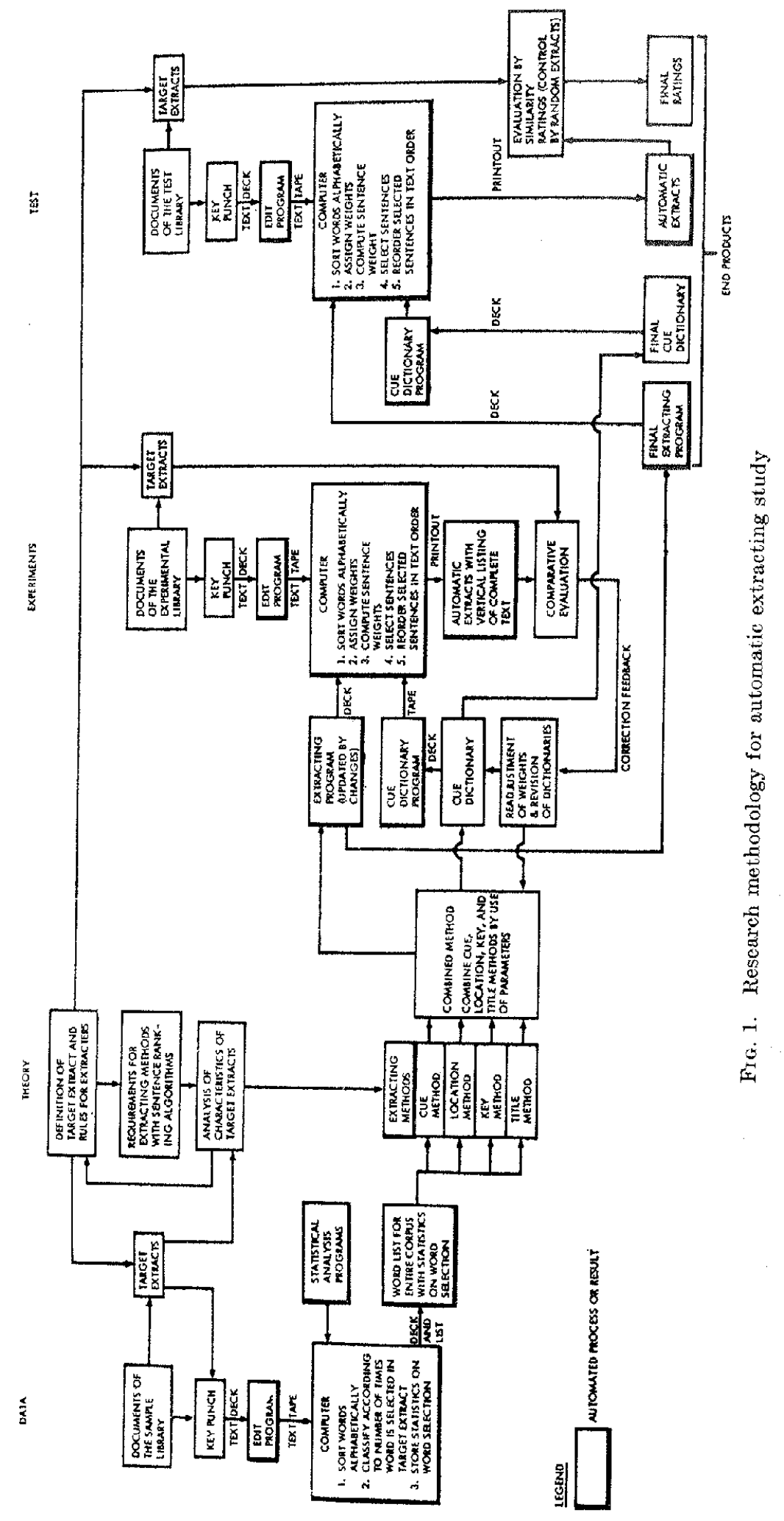


exist certain cluos that, independent of subject content, tend to indicate those sentences are significant. The goal was to replace the subjective notion 'ignificant" by an operational procedure. A methodology was sought whereby a puter could produce extracts as useful as conventionally created abstracts. approach was to look for selection criteria among manually selected and read sentences.

he research steps, in chronological order, were:

$y$ select a corpus of documents;

D) study the characteristics-both in terms of content and machine-recogniza-

- of traditional manual abstracts of documents;

i) specify the desired form and content of the "target" (manual) extracts;

- manually produce, for an experimental library of documents, target extracts ra eet both the content, and machine specifications;

i) develop a system that assigns numerical weights to machine-recognizable acteristics;

y) program a computer to produce automatic extracts;

. cyclically improve the program by comparing the automatic extracts and their ot extracts; and

3) evaluate the extracting system on a new group of documents not previously 1. in the experimental development. steps of the research methodology are shown in Figure 1.

Ex FCTION OF THE CoRpus. For the purpose of determining initial weights parameters, preliminary statistical data (on common words, sentence length, sentence position) werc obtained from 200 documents in the fields of physical nee, life science, information science, and the humanities; hercafter this colion is called the heterogeneous corpus.

ot the extracting experiments a different corpus, consisting of 200 documents hemistry, was used. These documents were contractor reports to various governat agencies and ranged in length from 100 to 3900 words, with an average of

D. The limitation on document length was imposed by the limited computer age available for the text of a document under the present program. These nical reports, written by chemists, chemical engineers, and physicists, were II formatted and terse, and contained equations and experimental data.

ince a fair evaluation of experimental results required that the system be tested cocuments different from those used in developing it, the chemistry corpus divided into an experimental library of documents to serve as the data base for experimentation, and a test library of documents reserved for evaluation he extracting program after experimentation had been completed.

A feget Extracts

pecification of Target Extracts. A set of instructions for human extractors a eveloped comprising the following specifications for the content and form he target extracts, and the systematic procedures for composing them.

- Sentences were selected only if they were eligible in terms of content. A sense was called eligible if it contained information of at least one of the following ty pes:

$\$_{\text {zibject Matter. Information indicating the general subject area with which }}$ a uthor is principally concerned (i.e. what?). 
Purpose. Information indicating whether the author's principal intent is to offer original research findings, to survey or evaluate the work performed by others, to present a speculative or theoretical discussion, or to serve some other main purpose (i.e. why?).

Methods. Information indicating the methods used in conducting the research. Depending on the type of research, such statements may refer to experimental procedures, mathematical techniques, or other methods of scientific investigation (i.e. how?).

Conclusions or Findings. Information indicating the author's conclusions or the research results.

Generalizations or Implications. Information indicating the significance of the research and its bearing on broader technical problems or theory.

Recommendations or Suggestions. Information indicating recommended courses of action or suggested areas of future work.

2. Sentences were selected to minimize redundancy in the extract. A sequence of sentences was said to be nonredundant if their information content was not repeated by reiteration, paraphrasing, or direct implication.

3. Sentences were selected to maximize coherence. A sequence of sentences was said to be coherent if all crucial antecedents and referents were present, no semantic discontinuities were present, and the sequence of ideas progressed logically.

4. The number of sentences selected was predetermined by a rule. Even though 25 percent of the sentences of the document was used as the length parameter for this research, this is not proposed as the optimal figure because it depends both on the purpose the extract is to serve and on the length and nature of the document.

An example of a target extract appears in Figure 2.

\section{Preparation of Target Extracts}

Analysis Procedure. To systematize the manual preparation of target extracts by humans, an analysis sheet itemizing every sentence was completed for each document. Here the extractor recorded his judgment about the eligibility of the sentence, his findings on its dependency on other sentences (e.g. antecedents), and whether the sentence was selected for the target extract. To facilitate comparisons, columns were also provided to record sentence selections by the various automatic methods and by a random-selection procedure used to evaluate the comparison scores described below.

Composition Problems. Much of the target-extracting effort was devoted to locating duplications of information throughout the document. A typical chemistry document had a summary at the beginning, an orientation section, a methods section, a discussion section, and, frequently, a conclusion that rephrased the initial summary. Hence the same information often appeared in several places in a document. Occasionally, however, nearly the entire document comprised research conclusions. When a hierarchy, either of significance or of generality, could not be established, no abstract could logically be composed by extracting. In this case a description representation was appropriate. However, if the document did contain a description of itself, this description rarely amounted to 25 percent of the sentences; if it did not, then the present extracting rules did not yield a coherent extract. Furthermore, to select 25 percent of the sentences, it was occasionally. necessary to select several less condensed sentences instead of an equivalent, but 
ABSTRACT BASED ON HUMAN SELECTION

EVALUATION OF THE ETFECT OF DIMETHYLAMINI BORINE AND SEVERAL OTHXR ADDITIVES ON CONGUSTION STABILITY CHARACTERISTICS OF VARIOUS HY OROCARBON TYPE FUIL IN PHILLIPS MICROBURNER (ADETTHO)

MICROBURNER

1 SUMMARY

2 I AT THE REQUE5T OF THE NAVY BUREAU OF AERONAUTICS, PHILLIPS PETROLEUM COMPANY UNDERTOOK THE EVALUATION OF DIMITHY LAMINE BORINE AS AN ADDITIVE FOR IMPR

2 BECAUSE OF THE SAMLI AHOUNT (100 GRAMS) OF DIMETHYLAMINE BORINE RECEIVED ME THE SAMMICAL COMPANY THIS TYALUATION HAS B EEN LTMITED TO THE MEASUREMENT OF ITS EE EECT ON THI TLASH-BACK CHARACTERISTICS OF THREE PURE HYDROCARBONS (TOLUENE, NORMAL REPTANE AND BENZENE) IN THE PHILLIPS MICROBURNER.

2 (3) DIMETHYLAMINE BORINE CONCENTRATIONS OF FROM 0.1 to 1.0 PER CENT BY WIGHT WERE EVALUATED.

FOR COMPARATIVE PURPOSES TWO COMMON IGNITION ADDITIVRS (AMY $L$ NITRATE AND CUMENE HYDROPEROXIDE) WERI ALSO EVA LUATED DURDE THIS STUDY, AS WELL AS CONCENTRATIONS UP TO 20 PER CENT BY WEIGHT OF PROPYLENE OXIDE. A RELATIVELY HIGH FLAME VELOCITY TUEL.

PAIVIOUS STUDIES IN PHILLIPS 2 INCH TURBOJET ENGINE TYPE COMBUSTOR HAD INDICATED THAT SUCH MATERULS GOULD SUBSTANTLLLY INCREASE THE MAXIMTSM RATE OF HEAT RELEASE ATTAINABLE. ESPECLLLY WITH LOW PERTORMANCE FUELS SUCH AS THE ISO PARAFTIN TYPE HYDROCARBONS - PARTICULARLY WHXN OPIRA TING UNDER SEVIRE CONDITIONS FOR COMBUSTION (2. $\mathbf{2}$., HIOH AIR YLOW VILOCITY OR LON COMBUSTION PRESSURE).

WITH RESPECI TO THE DIMETHYLAMINE BORINE, ITS EYTECT AS A TUEL ADDITIVE WAS NOTEWORTHY; O. I WEIGHT PER CENT IN TOLUENE BEING IOUNALENT TO 20 PER CENT BY WEICHT OF ADDED PROPYLENE OXIDE

15 IN GENERAL, ADDITIVE CONCENTRATIONS OF ONE PER CENT BX W EIGHT IN THE SEVERAI PURI HYDR OCARBONS WHICH NORMALLY DIFTIRED QUTTE WIDTLY IN PER. FORMANCE. PRODUCED UNIFORMLY SUPERIOR COMBUSTION STABILITY CHARACTERIS. TICS AS MEASURED USINC THE PHILLIPS MIEROBURNER

50 1. INTRODUCTION

8 Il. DESCRIPTION OF PHILLIPS MICROBURNER (MODEL IA)

UI. DESCRIPTION OF TEST APPARATUS

IV. DESCRIPTION OT TEST FUELS

THESE FUELS REPRESENT VARUTIONS IN CHEMICAL STRUCTURE WHICH WILL DN TURN PROVIDI

17 V. TEST PROCEDURE

21 0 VI, RESULTS

24

THX REGION OF STABLE OPERATION IS DEFINED AS THE STATE OF FLASH BACKTHX CONDITIONS OF COMBUSTION WRIRE THE FLAME WOULD BECOME ANCHORED TO A FAME HOLDER A AN IN SABLE GAS TURBNE OR RAM JET COMB
TION IT THE FLAME HOLDER WERT PROVIDED IN THE BURNER TUBE. vik. Discussion

THI ASSUMPTION TS MADE THAT THE GREATER THE ALLOW ABLE BEAT DPUT RATE AT A GIVIN VELOCITY. THE GREATER THL DEGREE OF STABILITY.

ALC FOUR ADDITIVES INDICATED THEIR ADDITTON TO BC SUBJECT TO THE EFTICT OF DEMINISHING'RESULIS UPON FURTHER ADDITION - THAT IS. THER ETFECT WAS

MENTION SHOULD BE MADE OF THE FACT THAT DURING THE COMBUSTION OF THE DIMETHY LAMINE BORINE.HYDROCARBON YUEL. BLENDS NO NOTICEAB LE ODORS OR
SMOKE WERE OBSERYED.

33 a vill. CONCLustons

$36 \quad 1$

3. THE ADDITION OY ADDITIVE CONCENTRATIONS (UP TO I PER CENT) OF AMYL NITRATE, CUMENE HYDROPERIOXIDE, AND DIMETHY LAMINE BORINE ALL RESULTTD IN LMPROVED STABILITY PERFORMANCE; THE GREATEST INCREASES WIRE SHOWN WHEN BLENDED WITH A FUEL OF POOR PERTORMANCE CHARACTERISTICS - SUCH AS
TOLUENE.

BENEFICLL EFFECTS WERX APPRICLALY LESS WHEN BLUNDED WITH A FUEL OF GOOD PER FORMANCE CHARACTERISTICS - SUCH ASN.HEPTANE IX. RECOMMENDATIONS

BASED ON THE EVALUATION OF THE EFTECTS OF ADDITIVES ON THE FIASHBACK LIMITS OF THE ADDITIVE-FUEL BLENDS TESTED IN THE MICROBURNER (MODEL IA) IT IS RECOMMENDED THAT DIMETHY LAMINE BORINE GHOULD BE FURTHER

THIS FUTURE WORK SHOULD INCLUDE STUDY OF COMBUSTION STADILITY AND COMBUSTION EFTICIENCY EFFECTS IN THE PHILLIPS 2 INCH COMBUSTOR AND AN 
more succinct, one. Although the 25 percent length pararneter seemed workable for most documents, in some cases it was manifestly not appropriate.

An attempt was made to classify eligible sentenees as to qualitative degree of "extract-worthiness" (a concept analogous to that of quantitative weightings). However, in practice it did not prove satisfactory for sentence selection since it was often impossible to determine if a sentence, seen only in the context of an extract, reported a well-known fact, a result of some previous experiment, or a conclusion of the document being extracted. Furthermore, a sentence was often anaphoric, i.e. depended on another one for its meaning (and there may even have been a series of such dependencies), requiring the selection of both even though the other sentence did not qualify in terms of content. Certain words or phrases such as "this," "therefore," and "since" frequently indicated this situation, and studying their occurrence seemed necessary to the refinement of the automatic method. The more an author used such words for reasons of structuring and style, the more difficult it was to extract sentences from context without destroying their function in the document.

In the composition of maximally coherent and meaningful target extracts, it was noticed that requirements of antecedents, delctions of text due to preediting, minimization of redundancy, and restrictions on the length parameter often took precedence over a sentence-by-sentence rating of extract-worthiness. In the evaluation step it was found that target extracts consistently differed from automatic extracts in precisely these aspects.

\section{Automatic Extracts}

Guiding Principles for Automation. The following principles were devised to guide the development of automatic extracting methods so as to yield close approximations to target extracts:

1. Detect and use all content and format clues to the relative importance of sentences that were originally provided by the author, editor, and printer.

2. Employ mechanizable criteria of selection and rejection, i.e. a system of reward weights for desired sentences and penalty weights for undesired sentences.

3. Employ a system of parameters that can be varicd to permit different specifications for extracts.

4. Employ a method that is a function of several linguistic factors (syntactic, semantic, statistical, locational, etc.).

Clearly, a computer can operate only on machine-recognizable characteristics of text (e.g. occurrence of certain words, position of a sentence in a paragraph, number of words in a sentence). A text characteristic was said to be positively relevant if it tended to be associated with sentences manually selected to comprise an extract, negatively relevant if it tended to be associated with unselected sentences, and irrelevant if it tended to be associated equally with selected and unselectcd sentences (see [5]). The task was to find relevant characteristics of the text and program the computer to recognize and weight them.

The Four Basic Methods. The automatic extracting systcm was based on assigning to text sentences numerical weights that were functions of the weights assigned to certain machine-recognizable characteristics or clues. For computational simplicity the sentence weights were taken as sums of the weights of these characteristics. The four basic methods (called Cue, Key, Title, and Location) to be 
discussed next used different sets of clues to the probable desirability of selecting a sentence for the automatic extract.

It was necessary to distinguish two types of word lists. A dictionary was regarded as a list of words with numerical weights that formed a fixed input to the automatic extracting system and was independent of the words in the particular document being extracted. A glossary was regarded as a list of words with numerical weights that formed a variable input to the automatic extracting system and was composed of words selected from the document being extracted.

1. Cue Method. In the Cue method the machine-recognizable clues are certain general characteristics of the corpus provided by the bodies of documents. The Cue method is based on the hypothesis that the probable relevance of a sentence is affected by the presence of pragmatic words such as "significant," "impossible," and "hardly." The Cue method uses the prestored Cue dictionary of selceted words of the corpus. The Cue dictionary comprises three subdictionaries: Bonus words, that are positively relevant; Stigma words, that are negatively relevant; and Null words, that are irrelevant. The final Cue weight for each sentence is the sum of the Cue weights of its constituent words.

The Cue dictionary was compiled on the basis of statistical data and refined by linguistic criteria. Initial statistical data were obtained from 100 documents of the heterogeneous corpus for which target extracts had been preparcd. A concordance program provided the following statistics for each word: frequency (number of occurrences in the corpus), dispersion (number of documents in which the word occurred), and selcction ratio (ratio of number of occurrences in extractor-selected sentenees to number of occurrences in all sentences of the corpus) (see [4]).

The following classes were then defined and listed by a computer program: Null candidates - dispersion greater than a chosen threshold and selection ratio between two chosen thresholds; Bonus candidates-selection ratio above the upper threshold; Stigma candidates - selection ratio below the lower threshold; and Residuedispersion less than the threshold and selection ratio between the thresholds.

These categories were modified in three further steps. First, since most of the counterintuitive assignments occurred with low-frequency words, certain words were reclassified on this basis as Residue. Second, the statistics for 20 documents of the chemistry corpus were examined, and those additional words that cxceeded a frequency threshold were also assigned, according to their selection ratio, to the Bonus, Stigma, and Null dictionaries. The final Cue dictionary contained 139 Null words, 783 Bonus words, and 73 Stigma words. The Null dictionary was created to list words excluded from the Key and Title glossaries, which are discussed next. Furthermore, it constituted a reservoir of common words that might, upon further research, be transferred to the Bonus or Stigma dictionaries.

Linguistic analysis of the experimental data revealed the following classes of Cue words: Null-ordinals, cardinals, the verb "to be," prepositions, pronouns, adjectives, verbal auxiliaries, articles, and coordinating conjunctions; Bonuscomparatives, superlatives, adverbs of conclusion, value terms, relative interrogatives, causality terms; Stigma-anaphoric expressions, belittling expressions, insignificant-detail expressions, hedging expressions; and Rosidue--positives, technical terms, and archaic terms.

2. Key Method. The principle (but not the algorithm) of the Key method is like the one first proposed by Luhn for crcating automatic extracts (see [6]). Its 
machine-recognizable clues are certain specitic characteristics of the body of the given document. It is based on the hypothesis that high-frequency content words are positively relevant.

The Key method compiles a Key glossary for each document, ideally consisting of topic words statistically selected from the body of that document. The words comprising a Key glossary were selected by listing all words not in the Cue dictionary in order of decreasing frequency of occurrence in the document. The frequencies were cumulated, from the highest downward, to a given percent of the total number of word occurrences in the document. Non-Cue words with frequencies above this threshold were designated Key words and were assigned positive weights equal to their frequency of occurrence in the document. The final Key weight of a sentence is the sum of the Key weights of its constituent words.

Initially, Key words were defined as non-Cue words of the highest Cue-weighted sentences, and their Key weights were taken to be their frequency of occurrence in that set. In the final system, Key words were chosen from a given percent of the total number of words in the document, and their Key weights were taken to be their frequency of occurrence over all words in the document. It was felt that the change from a fixed threshold to a fractional threshold was an improvement because of increased coverage and flexibility. Moreover, both statistical and linguistic investigations have supported the shift from the narrower environment of high Cue-weighted sentences to the wider environment of all text words.

3. Title Method. In the Title method the machine-recognizable clues are certain specific characteristics of the skeleton of the document, i.e. title, headings, and format. The Title method is based on the hypothesis that an author conceives the title as circumscribing the subject matter of the document. Also, when the author partitions the body of the document into major sections he summarizes it by choosing appropriate headings. The hypothesis that words of the title and headings are positively relevant was statistically accepted at the 99 percent level of significance.

The Title method compiles, for each document, a Title glossary consisting of all non-Null words of the title, subtitle, and headings for that document. Words in the Title glossary are assigned positive weights. The final Title weight for each sentence is the sum of the Title weights of its constituent words.

The weights assigned to the words of a Title glossary were determined on the basis of their effect in the combined weighting scheme of the four methods. Content words of the title were given heavier weights than content words of the headings. However, the initial assignment of weights led to a difficulty in the ranking of all sentences of the document when the Title method was used, since one weight was an exact multiple of the other, and this caused many ties among sentence weights. To minimize the occurrence of ties, title words were assigned a weight relatively prime to that of heading words.

4. Location Method. In the Location method the machine-recognizable clues are certain general characteristics of the corpus provided by the skeletons of documents, i.e. headings and format. The Location method is based on the hypotheses that: (1) sentences occurring under certain headings are positively relevant; and (2) topic sentences tend to occur very early or very late in a document and its paragraphs. These location characteristics of sentences were tested for correlation with selection ratios, and statistically derived weights were assigned to reflect the 
probable relevance of sentences according to their occurrence under certain headings and their position in a document and a paragraph.

The Location method uses the prestored Heading dictionary of selected words of the corpus that appear in headings of documents, e.g. "Introduction," "Purpose," "Conclusions." In addition to assigning positive weights provided by the Heading dictionary, the Location method also assigns positive weights to sentences according to their ordinal position in the text, i.e. in first and last paragraphs, and as first and last sentences of paragraphs. The final Location weight for each sentence is the sum of its Heading weight and its Ordinal weight.

To investigate the importance of headings for a sentence, all words occurring in the headings of 100 documents of the heterogeneous corpus and 20 documents of the chemistry corpus were listed, excluding prepositions, articles, and highly specific words. A set of words was common to both corpora, and a selection ratio was computed for each. Selection ratios were found to confirm the intuitive appraisal of heading-word importance. Weights proportional to the selection ratios were then assigned to each of these heading words, and the remaining heading words were assigned the same weights as their synonyms in that set. Deletions were made on the basis of low frequency and unrelatedness to the desired information types (i.e. subject, purpose, method, conclusion, generalization, recommendation). The resulting Heading dictionary contained 90 words.

To investigate the importance of sentence position-both within a paragraph and in the document as a whole- 300 sentences were randomly picked from the heterogeneous corpus, and selection ratios computed. These data were used as the basis for the assignment of Ordinal weights to the positional characteristics of a sentence according to whether it occurred in the first paragraph, last paragraph, and as first sentence, or last sentence. Intermediate sentences and paragraphs were assigned zero weights. The final weights adopted reflected the gross behavior of the above selection ratios.

Rationale of the Basic Methods. Extracting clues may come from two structural sources: (1) the body (text) of the document; and (2) the skeleton (title, headings, format) of the document. Also, clues may come from two linguistic sources: (1) general characteristics of the corpus and language (e.g. value-judgment words); and (2) specific characteristics of the individual documents (e.g. high-frequency words).

The two structural sources and the two linguistic sources of clues yielded four opportunities to create basic methods of automatic extracting which were defined simply by the class of clues upon which they rely. When applied to word clues this classification yielded four distinct word lists. These distinctions and standardizations of terminology permitted the following convenient classification of the four methods and their corresponding word lists (see Figure 3).

Experimental Cycles. Seventeen experiments were performed in the course of the research to verify the significance of the various extracting clues, to refine the Cue and Heading dictionaries, to adjust weights, to reprogram the four basic methods, to improve the output format, and to evaluate the extracting methods (singly and in all possible combinations).

In the final system the relative weights among the four basic methods were parameterized in terms of the linear function

$$
a_{1} C+a_{2} K+a_{3} T+a_{4} L
$$




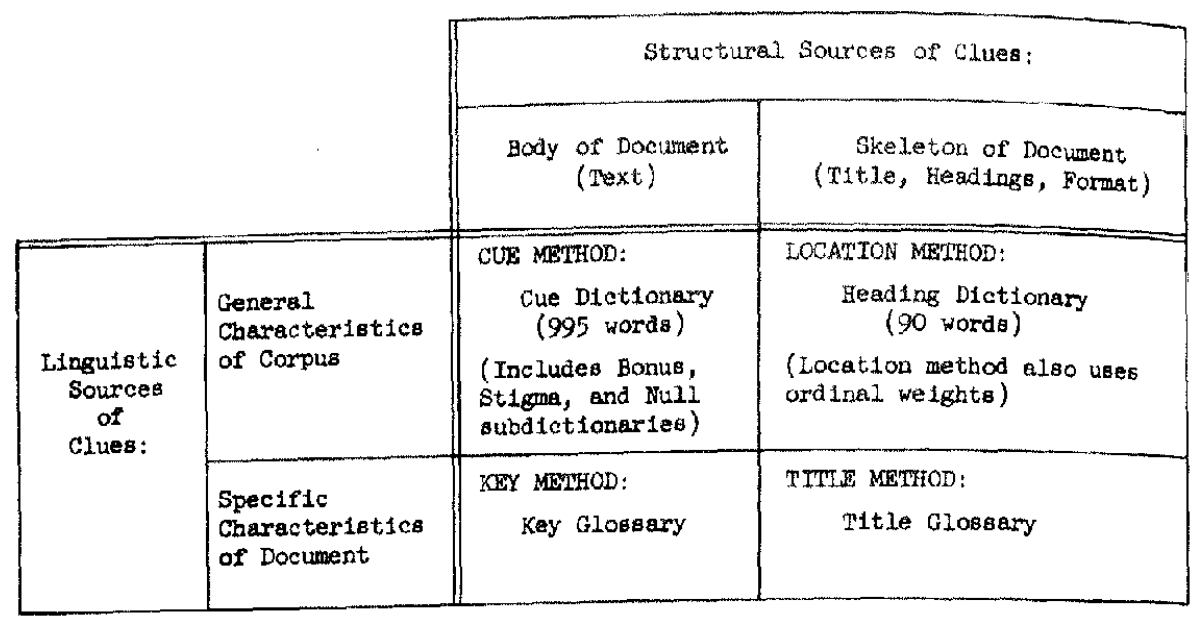

Fra. 3. Rationale of the four basic methods

where $a_{1}, a_{2}, a_{3}$, and $a_{4}$ are the parameters (positive integers) for the Cue, Key, Title, and Location weights, rospectively. Moreover the length parameter $P$ was modified so that it can be adjusted to any integral percent of the number of sentences in a document. Thus by means of a single program card, the values of $a_{1}, a_{2}, a_{3}, a_{4}$, and $P$ can be specified as desired. Also, the 7090 -7094 system was modified to extract documents of 4000 words instead of 3000 words (as initially programmed).

Selection of Preferred Method. The percent of the number of sentences coselected in both the automatic and the target extracts was computed for each of the extracting mothods, separately and in combination. The mean percentages for the most interesting methods are shown in Figure 4, with the intervals encompassing the sample mean plus and minus one sample standard deviation. The corresponding percentages for the random extracts (i.e. a random selection of 25 percent of the sentences) and the automatic extracts are given for comparison. The CueTitle-Location method is seen to have the highest mean coselection score, while the Key method in isolation is the lowest of the automatic methods.

On the basis of these data it was decided to omit the Key method as a component in the preferred extracting system. These data confirm the hypothesis set forth

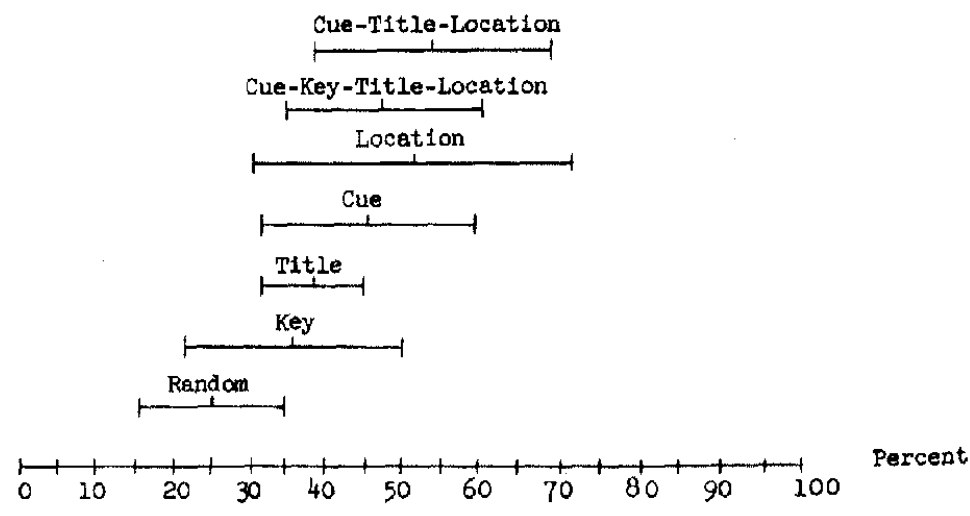

Frg. 4. Mean coselection scores of the methods 


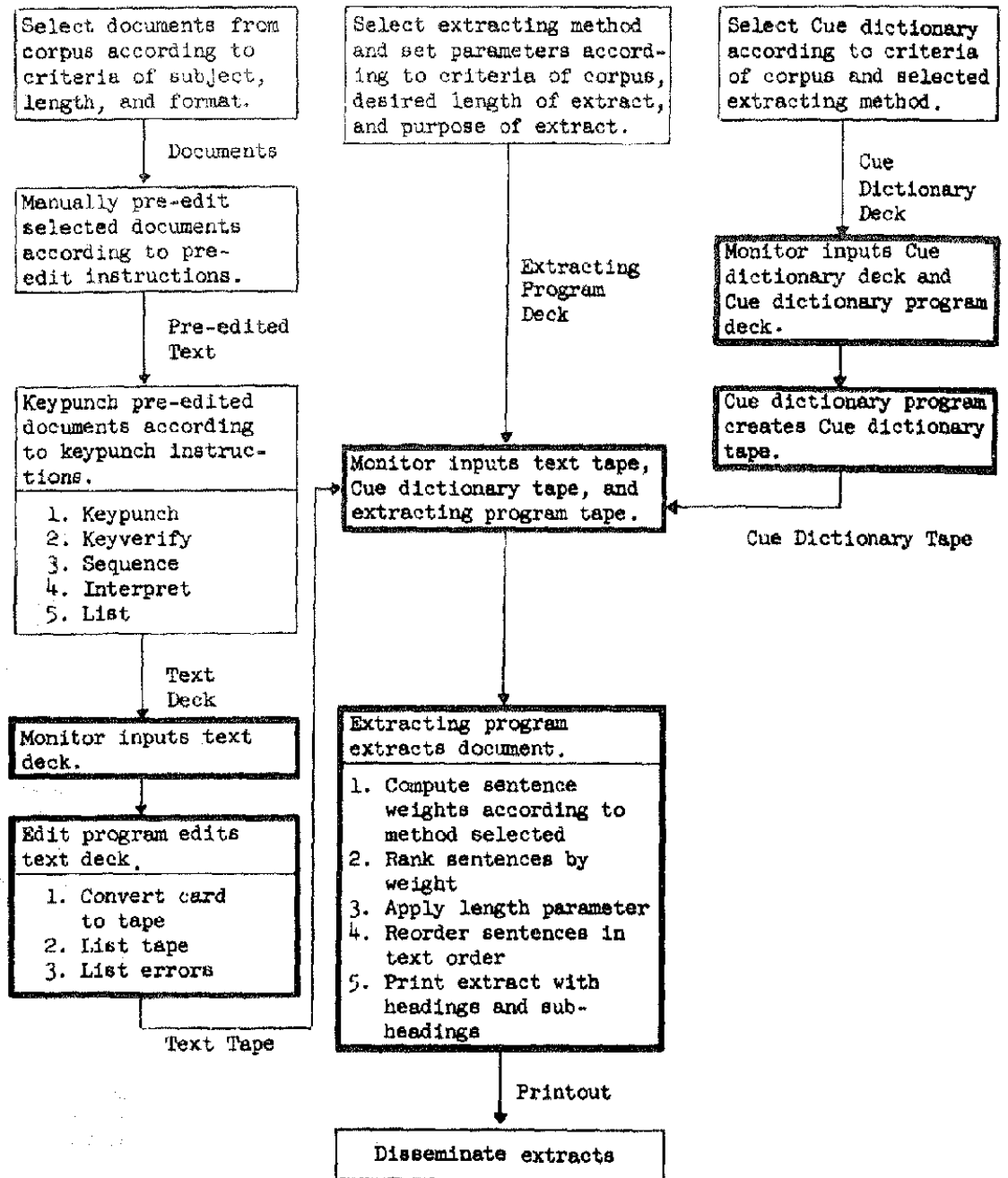

Note: Heavy boxes denote computer operations

Fra. 5. Fixtracting system

preedited according to preedit instructions, which cover the problems of formatting, graphics, special symbols, special alphabets, etc. Figure 6 shows a preedited document. The notations used are defined and discussed in [1].

Keypunching. The keypunch instructions are based on the preedit instructions and are subject to the conditions imposed by present input and output hardware. They contain rules and examples of sufficient generality to cover a wide varicty of textual situations.

Edit Program. The edit program creates the text tape used by the extracting program. Text written in free format is punched on cards according to the keypunch instructions. The edit program interprets these cards, recognizing title, headings, author, paragraph boundaries, sentence boundaries, number of sentences in document, punctuation, capitalization, etc. The program also recognizes input errors, which are then printed together with a vertical listing of text described below. 
4x

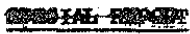

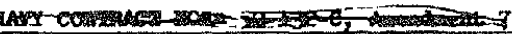

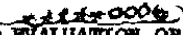

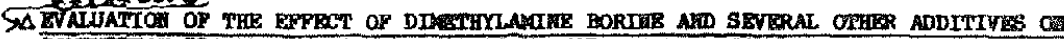

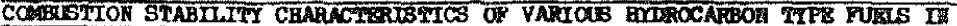

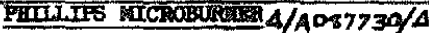

\section{$\rightarrow$ R. L. Brace

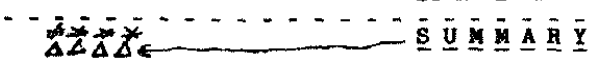

At the request of the havy Bureau of Aeronauties, Fhillips Petroleur Corpany undertook the evaluation of dinethylasine boribe as an additive for isproving the combustion characteristics of avlation gas turbine type fuels. Because of the small sount ( 100 grams ) of dimethylamine borlne received from Callery Chesical Coupeny, this evaluation has been linited to the messurenent of its effect on the Plash-back characteristics of three pure hydrocarbone (toluene, normal beptane and benzene) in the Phillips Mcroburner. Dimethylanine borine concentrations of rram 0.1 to 1.0 per cent by veight vere evaluated.

For comparative pupposes two cosmon ignition additives (acyl nitrate and cumene hydroperaxide) vere also evaluated during this study, as vell as cancentratlons up to 20 per cent by velght of propylene oxide - a relatively high rlame veloc1ty fuel. . Pxevious studies in Philitps 2 inch turbojet englne type conbustor had indicated that such saterials could substantially increase the waximu rate of beat release attainable, especially with low perforwance fuels such as the iso paraffin type hydrocarbons - particularly when operating under severe conditions for combustion (1.e., blgh alr flow velocity or low combustion pressure).

The assimation has been ande in this fuel evaluation that the greater the allowable heat input rate for a given velocity, the greater the degree of combustion stablifty. On this basis, the data indicate that all the additive materials tested caused an increase in stability performance; a fuel of relatively low performance buch as toluene being benefited to a greater extent tban a high performance fusel such as norwal heptane. These data are in agreenent with previous additive studies by Phlilips. With respect to the dimethylmine borine, its effect as a tuel additive was noteworthy; 0.1 veight per cent in toluene belng equivalent to 20 pex cent by weight of added propylene oxlde. In general, additive concentrations of one per cent by weight in the several pure hydrocarbons which norwally differed quite ridely in performance, produced uniformly superior combustion stability characteristics as measured us ing the Folllips Microburner.

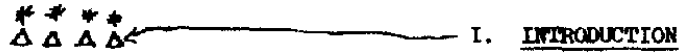
At the request of the Navy Bureau of Aerorautics the Jet Puels Group has
45 evaluated the effects of the addition of smoll amounts of dimethylamine borine $\left(\left(\mathrm{CH}_{3}\right)_{2} \mathrm{NH}: \mathrm{BH}_{3}\right)$ on the combustion stability performance of several hydrocarbon fuels? The dimethylamine borine vas supplied to Phillips by the Callery chemical Company .

Bue to the small quantily "i this material obtained the evaluation vas conducted in the Phillips Microburver (Model IA) which is a slichtly modified version of the original Phillips Microburner (Model 1).

Frr. 6. Preedited document (cont'd on next page)

Cue Dictionary Program. The Cue dictionary program creates a Cue dictionary tape to be used by the extracting program when it is identifying Cue words and compiling the Key and Title glossaries. The input to the program consists of at most 1000 words and their weights; the words are punched one word per card and must be in alphabetical order. The output consists of a binary tape containing only one record, in which each entry takes four computer words. Certain input errors can be detected, and these, as well as a BCD listing of the Cue dictionary, are printed on an output tape.

\section{Processing Steps}

\section{Cue Method:}

1. Comparc each word of text with Cue dictionary. 


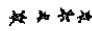

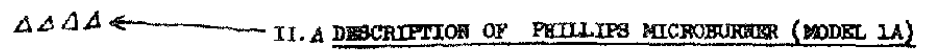

The design of the origtnal Fhillips Heroburmer (Nodel 1) was discussed in detail in Reference 1 . The only glgatificant cbange in burner detail val the

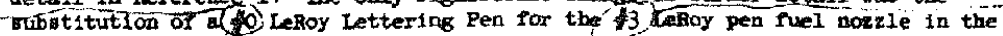

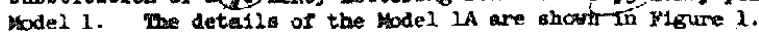

* *

$\Delta \Delta \Delta A \leftarrow$ III. DESCRIPTIOK OF TEST APPARATUS

The fisel systesn on the Fhill1ps Microbumer (bodel 1) vas desigaed so as to handle seall quantities of highly corrasive aubstances. In the present evaluation it yas not necessary to consider the effect of carrosion, consequentiy a continuous flow sybtes providing greater flexibility and easier handing was incorporated which requires only alfihtly wore fuel per test then the original. This new systes laneludes a source of aitrogen gas, a surge tank, a pressurized fuel tank, a abali capacity Brooks Rotameter and a flow cootrol valve.

The alr beter c1rcuit was wodified so as to include a percury relay and bi. petallic therzousteh thus providing autconatic als tempereture control.

The details of these modifications and of the teat apparatus are show in Bchematic in Mgme 2 .

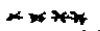

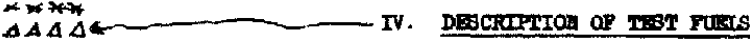

The chesical and physical properties of the bydrocarbon fluels teated are sumarized in Table I. These fuels represent variations in chenical structure vich vill in tim provide indices of both good and poor combustion stability performance.

The additives evaluated, dimethylasine borine, propylene oride, anyl aitrate cuave bydroperaxide, vere blended into the hydrocarbon fuel by vefight in concentrations ranging fror 0.1 to 20 per cent.

$\triangle \Delta \Delta A \leftarrow$ THST PROCEDUWE

The conditions at wich this study was made in the kicroburner (model $1 \mathrm{~A}$ ) vere: $\$$ T.

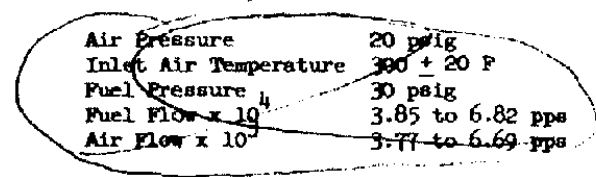

Once the air temperature was established the air flow was set at the desired rate and the nel turned on. Ignition of the then fuel-rich mixture vas accomplished. by applying a lighted, portable propane torch to the top of the burner tube. The nel now was then gradually decreased until the flame holding at the burner tube rim flasbed back into the tube. At the point of Hasbback the following vere recorded:

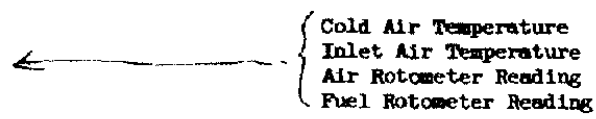

Arter checking the point at least once wore the air flow was increased another increment and the process repeated.

\section{FIG. 6 (continued)}

2. Tag all Bonus words with weight $b>0$, all Stigma words with weight $s<$ 0 , all Null words with weight $n=0$.

3. Compute Cue weight $C$ of each sentence by summing its Cue word weights $b, s$, and $n$.

4. Rank all sentences in decreasing weight order.

5. Select sentences whose rank order is less than length parameter $P$ percent of the number of sentences in the document.

6. Select all headings.

7. Merge selected sentences under their proper headings.

8. Output title, authors, and results of step 7. 
Key Method:

1. Compare each word of text with Cuc dictionary.

2. Create table of distinct, nonmatching text words (as Key-word candidates).

3. Compute frequency $k$ of each Key-word candidate.

4. Sort table in decreasing frequeney order.

5. Create a Key glossary from all Koy-word candidates whose total frequency (when summed in decreasing frequency order) cxceeds threshold of $W$ percent of the total number of word occurrences in document.

6. Compare cach text word with Key glossary, and tag each matching word with weight $k$ equal to its frequency of occurrence in text.

7. Compute Key woight $K$ of each sentence by summing its Key-word weights $k$.

8. Rank all sentences in decreasing weight order.

9. Select sentences whose rank order is less than length parameter $P$.

10. Select all hoadings.

11. Merge selected sentences under their proper headings.

12. Output title, authors, and results of step 11.

T'itle Method:

1. Compare each word of title and headings with Null dictionary.

2. Create a Title glossary of nonmatehing words.

3. Tag all words of Title glossary that come from title with weight $t_{1}$. Tag all words that come only from the subtitle or heading with weight $t_{2}$.

4. Compare each word of text with Title glossary. Tag each matching word with corresponding weight, $t_{1}$ or $t_{2}$.

5. Compute Title weight $T$ of each sentence by summing its word weights.

6. Rank all sentences in decreasing weight order.

7. Select sentences whose rank order is less than length parameter $P$.

8. Select all headings.

9. Merge selected sentences under their proper headings.

10. Output title, authors, and results of step 9 .

\section{Location Method:}

1. Compare each word of headings with Heading dictionary.

2. Tag each matching word with weight $h$ given in Heading dictionary.

3. Compute Heading weight $H$ ol each heading by summing its Heading-word weights $h$.

4. Tag each sentence with Heading weight $H$ of its heading.

5. Tag cach sentence of first paragraph with Ordinal weight $O_{1}$ and of last paragraph with Ordinal weight $\mathrm{O}_{2}$. Tag first sentence of every paragraph with Ordinal weight $O_{3}$ and last sentence of every paragraph with OrdinaI weight $\mathrm{O}_{4}$.

6. Compute Ordinal weight $O$ of each sentence by summing its Ordinal weights $\mathrm{O}_{1}, \mathrm{O}_{2}, \mathrm{O}_{3}$, and $\mathrm{O}_{4}$.

7. Compute Location weight $L$ of each sentence by summing its Heading weight $H$ and Ordinal weight $O$.

8. Rank all sentences in decreasing weight order.

9. Select all sentences whose rank order is less than length parameter $P$

10. Select all headings. 
11. Werge selected sentences under theil proper headings.

12. Output title, authors, and results of step 11.

Combined Methods. The four basic methods described above yield 15 combined methods that have in common the following sequence of steps:

1. Select desired values for parameters $a_{1}, a_{2}, a_{3}, a_{4}$, and $P$.

2. Compute total weight $a_{1} C+a_{2} K+a_{3}{ }^{\prime}+a_{4} L$ of cach sentence by summing its weighted single-method weights $C, K, T, L$.

3. Rank all sentences in decreasing weight order.

4. Select sentences whose rank order is less than length parameter $P$.

5. Select all headings.

6. Merge selected sentences under their proper headings.

7. Output title, authors, and results of step 6.

\section{Output Procedures}

Extracting Output. An extract of a document can be produced by any combination of the four basic methods of calculating sentence weights. The extracting output is an extract containing the following information: document number, methods used to produce the extract, title of the document, author(s) of the document, all headings (identified by zero as a sentence number), and the selected sentences (all tagged with paragraph and sentence number). Figure 7 shows an automatic extract produced by the combined Cue-Title-Location method.

\section{Research Output}

1. Key-word lists. Two lists of Key words for the document are printed, one in frequency order and the other in alphabetical order.

2. Sentence-weight lists. Two lists are printed, giving each sentence number in the document and its computed weight. One is in sentence order and the other in weight order. The weight is the sum resulting from the method or methods used.

3. Vertical listing. A list is printed, one word to a line, of every word (of the document) in text order together with punctuation before (open quotation mark, open parenthesis, initial capitalization, etc.), first punctuation after (comma, hyphen, period, etc.), second punctuation after (hyphen, closed parenthesis, closed quotation mark, etc.), paragraph number, sentence number within the paragraph, word number within the sentence, Cue weight, Key weight, and Titlo weight. After the last word of each sentence is printed, the Cue, Key, Title, and Location weights for that sentence are printed.

Trme and Cost FAcrors. Automatic extracts were produced by the combined Cue-Title-Location method at a minimum rate of 7800 words per minute on a corpus of 29,500 words. After the first 4000 words the rate increases linearly with the size of the corpus.

The total system cost (edit, extracting, output) was approximately 1.5 cents per word; keypunching costs (including verification) accounted for two-thirds of this. The above times and costs concern the present research only and should not be misinterpreted in connection with the question of the economic feasibility of automatic extracting.

\section{Outlook}

This research should be regarded as an interim report. Nonetheless, the direction of future investigation and the problems to be investigated next are becoming clearer. 


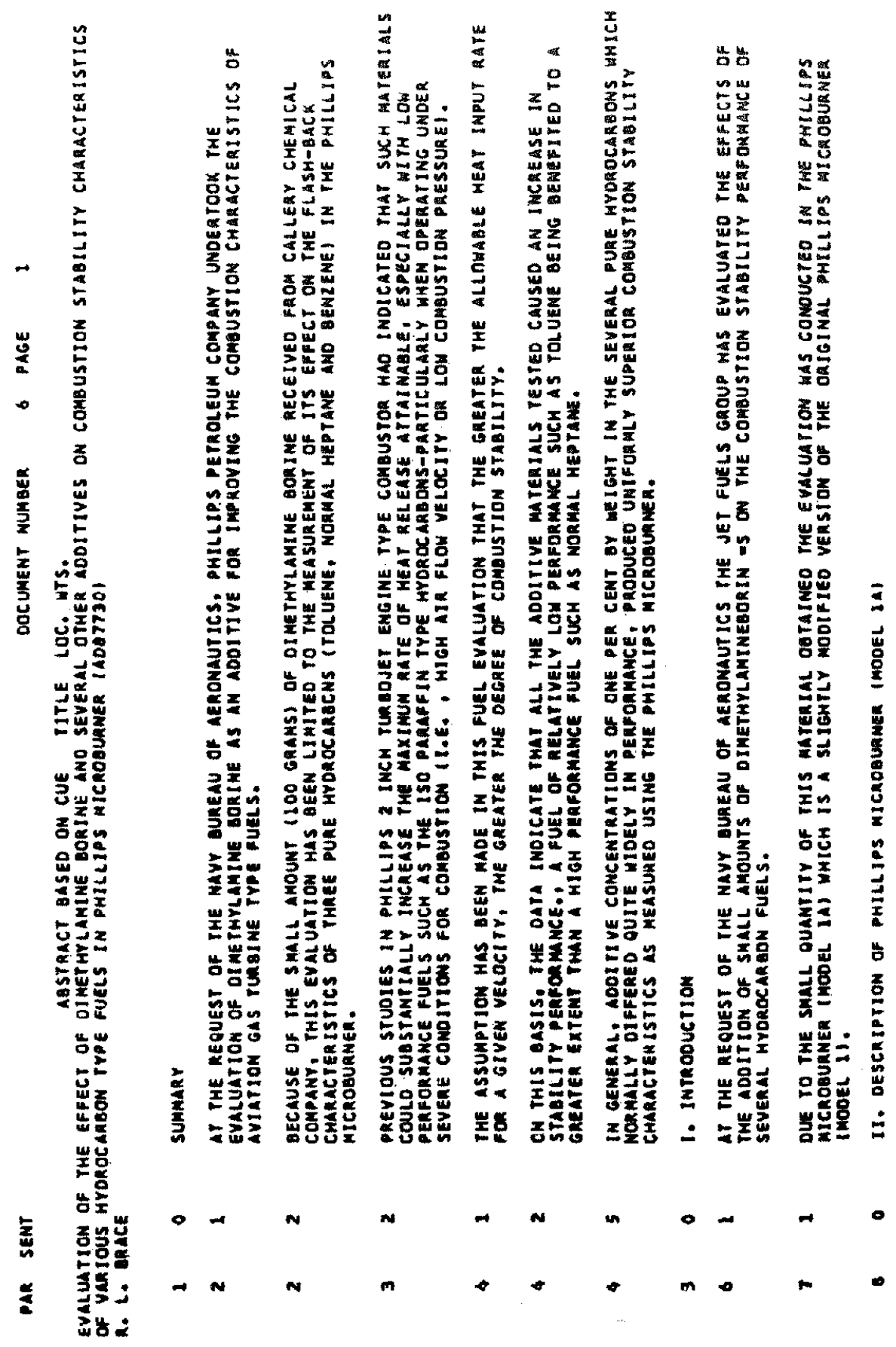




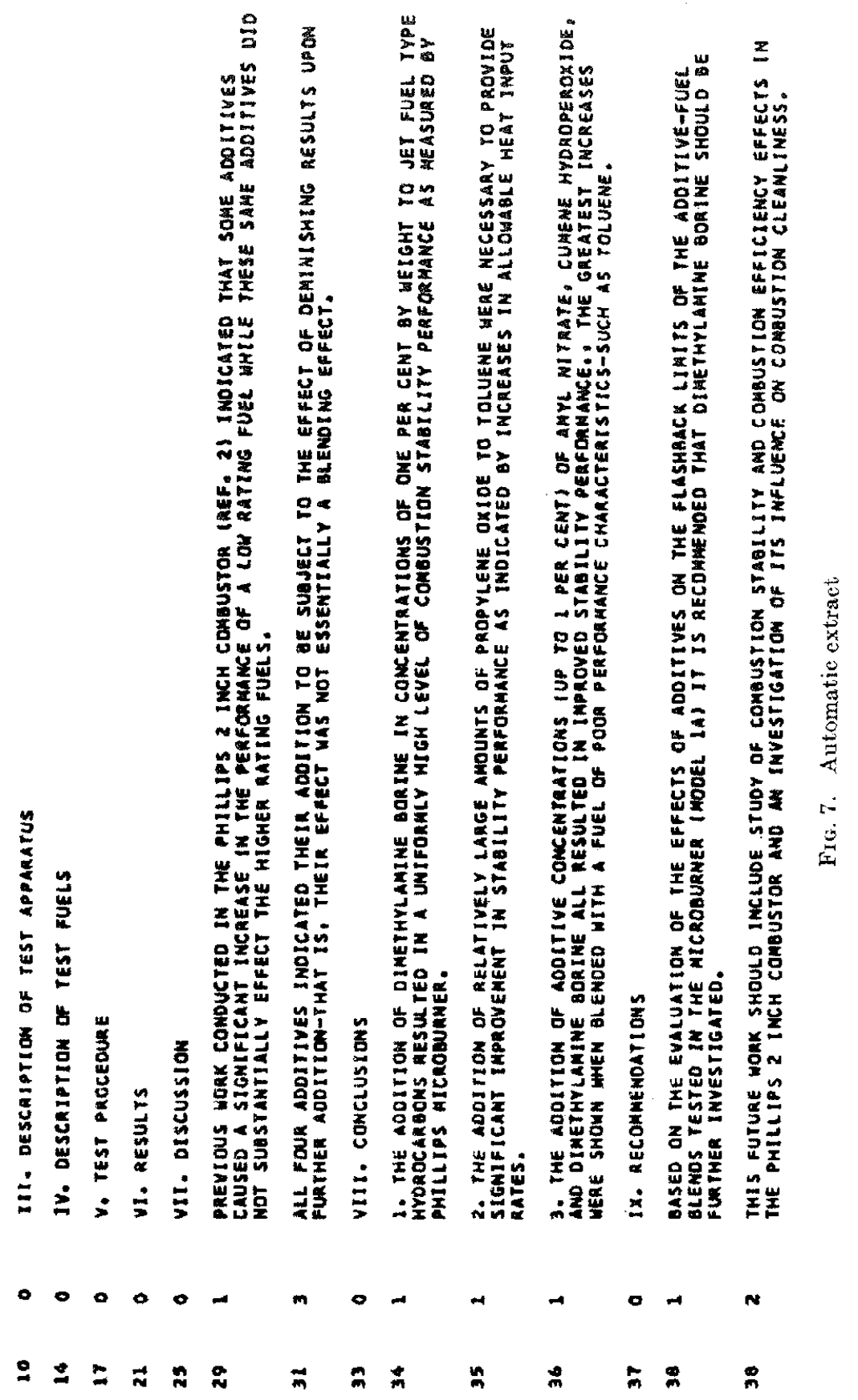


It is now beyond question that future automatic abstracting methods must take into account syntactic and semantic characteristics of the language and the text: they cunnot rely simply upon gross statistical evidence.

It is believed that the research methodology outlined here has been, and will continue to be, fruitful. Future research should adhere to the principle of parameterization to gain flexibility and permit continuing improvement of abstracting methods. The present set of weights is subject to continuing experimentation to permit maximum specification of desired content of automatic extracts. Even now ways can be conceived to reduce both the number and size of experimental cycles with more powerful statistical and computational techniques.

It is highly desirable that the extracting system be modified to accommodate longer documents (in fact it has been reprogrammed for the UNrvac 1103A to accommodate documents of approximately 40,000 words). To reduce operating time and costs, ways to make the programs more efficient should be investigated. Reprogramming can help, but the greatest need for improvement is in the method of inputting text. In this conmection it is also important to devise ways of automatically capturing chemical and mathematical symbols in machine form. Clearly there are extracting clues that have not yet been exploited-in captions of figures and tables, in footnotes and reforences, and in larger linguistic structures such as phrases and clauses. Better ways must be sought to identify those specific characteristics of documents that are significant for automatic extracting (such as presence or lack of headings, technical or literary content, etc.) and to correlate these characteristics with some combination of extracting method, set of weights, and length parameter that will give better automatic extracts.

Further investigation of methods of evaluating automatic extracts is needed to increase their speed, simplicity, and discrimination. Future research should involve sharper statistical analysis of the two types of error with the purpose of modifying the program to minimize them. Study should be made to discover machine-recognizable elues to determine the proper length of an extract. The extent to which redundancy appears in automatic extracts and ways of minimizing it should be inves. tigated. Linguistic clues to coherence should be identified and expressed in machine-recognizable form, perhaps in the form of a word-and-phrase dictionary indicating the need for selecting antecedent sentences. In summary, the main differences between manual and automatic extracts can now be described and procedures outlined to minimize them.

Although automatic extracts of the future may differ both in content and appearance from traditionally composed manual abstracts, these differences do not appear as insuperable barriers to their usefulness. In spite of the recognized problems it is now felt that automatic extracts can be defined, programmed, and produced in an operational system to supplement, and perhaps compete with, traditional ones.

Acknowledgments. The author especially acknowledges the work of his colleagues Mr. J. L. Kuhns, who conducted mathematical and linguistic research; Dr. P. L. Garvin, who assisted in dictionary compilation; Mrs. L. Ertel and Mr. D. Dwiggins, who performed the programming; and Mrs. J. Brewer, who conducted the content analysis.

\section{REFLRENCES}

1. Automatic abstracting. RADC-TDR-63-93, TRW Computer Div., Thompson-RamoWooldridge, Ine., Canoga Park, Calif, , Feb. 1963. 
2. Enmundson, II. P. Problems in automatic abstracting. Comm. ACM 7,4 (Apr. 1964), 259-263.

3. Eomendson, H. P., AND Wrours, R. E. Automatic abstracting and indexing-survey and recommendations. Comm. ACM 4, 5 (May 1961), 226-234.

4. Final report on the study for automatic abstratting. C107-1U12, Thompson-RamoWooldridge, Inc., Canoga Park, Calif., Sept. 1961.

5. Kunns, J. T. An application of logical probability to problems in automatic abstracting and information retrieval. Joint Man-Computer Indexing and Abstracting, Sess. 13, First Congress on the Informalion Sysiem Sciences, Nov. 1962.

6. Lurn, H. P. The automatic creation of literature abstracts. IBM $J$. Res. Develop. \&, 2 (1959), 159-165.

7. Rate, G. J., Resnick, A., and Savage, T. R. Comparisons of four types of lexical indicators of content. Amer. Docum. 12, 2 (Apr. 1961), 126-130.

RECEIVED JCLY, 1968 